Journal of Current and Advance Medical Research

July 2017, Vol. 4, No. 2, pp.48-52

http://www.banglajol.info/index.php/JCAMR

ISSN (Print) 2313-447X

ISSN (Online) 2413-323X

DOI: http://dx.doi.org/10.3329/jcamr.v4i2.36355

ORIGINAL ARTICLE OPEN ACCESS

\title{
Effect of Saline Sonosalpingography in Unexplained Infertility
}

\author{
Jannat Ara Ferdows ${ }^{1}$, Israt Jahan ${ }^{2}$, Zobaida Sultana Susan ${ }^{3}$
}

\begin{abstract}
${ }^{1}$ Assistant Professor, Department of Obstetrics \& Gynaecology, Shaheed Suhrawardy Medical College, Dhaka, Bangladesh; ${ }^{2}$ Assistant Professor, Department of Obstetrics \& Gynaecology, Shaheed Suhrawardy Medical College, Dhaka, Bangladesh; ${ }^{3} J u n i o r$ Consultant, Department of Obstetrics \& Gynaecology, Shaheed Suhrawardy Medical College and Hospital, Dhaka, Bangladesh
\end{abstract}

[Reviewed: 30 January 2017; Accepted on: 10 March 2017; Published on: 1 July 2017]

\section{Abstract}

Background: Saline sonosalpingography is a simple technique that has previously proved to be one way of increasing the chance of achieving pregnancy for couples with unexplained infertility. Objective: The purpose of the present was to evaluate the pregnancy rate following saline sonohysterography in stimulated cycles for couples with unexplained infertility. Methodology: This study was designed as prospective randomized controlled trial which was carried out for a period of two years from January 2015 to December 2016. Women with unexplained infertility were selected randomly for saline sonosalpingography and the procedure was carried out three to four days before ovulation in stimulated cycle. Outcomes measure were rate of pregnancy, first trimester abortion, multiple pregnancy, ectopic etc. Result: In this study total number of 55 patients were recruited for this study and saline sonosalpingography was performed over 2(two) years. Age range was from 23 to 42 years. Maximum patients are within the age range of 23 to 27 years. Among 55 patients, 23 were pregnant. Pregnancy rate was $41.81 \%$ cases. Singleton pregnancy without any complication was $52.17 \%$ cases. Twin pregnancy rate was $13.01 \%$ cases. Among them twin with single fetus demise was $4.3 \%$ cases, missed abortion $21.7 \%$ cases and ectopic was $8.7 \%$ cases. Conclusion: With good case selection, therapeutic hydrotubation may be beneficial in resource poor countries, especially in patients with incomplete tubal occlusion bilateral perifimbrial adhesions and as part of treatment for unexplained infertility. This demonstrates increased chance of pregnancy in this group. So further evaluation is needed to upgrade the result of the study. [Journal of Current and Advance Medical Research 2017;4(2):48-52]

Keywords: Sonosalpingography; hydrotubation; unexplained infertility; transvaginal sonography

Correspondence: Dr. Jannat Ara Ferdows, Assistant Professor, Department of Obstetrics \& Gynaecology, Shaheed Suhrawardy Medical College Hospital, Sher-e-Bangla Nagar, Dhaka, Bangladesh; Email: daisy71.jf@gmail.com; Cell no.: +8801711665929

Cite this article as: Ferdows JA, Jahan I, Susan ZS. Effect of Saline Sonosalpingography in Unexplained Infertility.Journal of Current and Advance Medical Research 2017;4(2):48-52

Conflict of Interest: All the authors have declared that there was no conflict of interest.

Funding: None

Contributions to authors: JAF, IJ \& ZSS have contributed in protocol preparation up to procedures as well as the report writing; furthermore, they have written the manuscript and have revised the manuscript.

Copyright: @2017. Ferdows et al. Published by Journal of Current and Advance Medical Research. This article is published under the Creative Commons CC BY-NC License (https://creativecommons.org/licenses/by-nc/4.0/). This license permits use, distribution and reproduction in any medium, provided the original work is properly cited, and is not used for commercial purposes. 


\section{Introduction}

Infertility is a major gynecological problem with complex etiology and about $10 \%$ cases remain unexplained after investigation ${ }^{1}$. Investigation of infertility is initiated after one year of attempt to conceive spontaneous pregnancy. During such an investigation blood sample are taken counting the basal hormone level and the ovulatory function in the female. The male partner only has a sperm count carried out. Ovulation can be detected by history of menstrual cycle regularity, hormone profile of serum follicle stimulating hormone, serum leutinizing hormone, serum prolactin and thyroid hormone. Ovulation can be further confirmed by ovulation detecting strips. A couple is said to have unexplained infertility if the investigations are within normal limit ${ }^{2}$.

The treatment of unexplained infertility is empirical and different regiments have been tried. The first line approach to treat unexplained infertility is to stimulate oocyte production by ovarian stimulation with multi-follicular development in most cases which may result in enhanced fertility ${ }^{4,5}$.

Tubal disease is considered to be the major underlying cause in unexplained infertility ${ }^{2}$. Significantly improved conception rate has been achieved by saline sonosalpingography in unexplained infertility ${ }^{5-7}$. Tubal flushing has previously proved to be one way of increasing the chance of acheiving pregnancy for couples with increased infertility and early stage of endometriosis ${ }^{8}$. Hydrotubation treatment can be administered in an outpatient clinic and represents a less invasive treatment alternative ${ }^{9}$. The effect of hydrotubation on fertility can be mechanical as well as immunological like inhibited phagocytosis of spermatozoa and by affecting level of peritoneal factors such as cytokines ${ }^{10}$. It can act by dislodgement of debris in fallopian tubes or by separating the loose adhesion of the tubes. It can also remove thick hostile cervical mucus which may hinder the passage of sperms through the cervix ${ }^{9}$. There may be stimulation of peristalsis by flushing of fluid and dilution of toxic factors such as cytokines in endometriosis ${ }^{7}$. The adverse effect of hydrotubation could be ectopic pregnancy, increased risk of infection, severe nausea, vomiting and peritonitis ${ }^{10-12}$. Saline sonosalpingography is carried out in most infertility investigation and the adjuvant effect of this examination on achieving spontaneous pregnancy is clinically well documented.
Saline sonosalpingography is transcervical flushing of fluid through the fallopian tubes. This technique has been used to test the patency of fallopian tubes and has been found to improve conception rate in infertile couples. Patency of tubes is confirmed by lack of resistance to the passage of fluid through the cervix, collection of fluid in the pouch of doglus and right shoulder tip pain. This technique is cost effective, cheap and easy to perform and does not require any special arrangement like theatre facilities. It is now being used in different low resource countries of the world ${ }^{2-5}$.

This study based on the hypothesis that women having unexplained infertility could be helped by hydrotubation which would remove reversible blocking factors and hostile elements and result in achieving pregnancy. The present study was carried out to investigate the effect on pregnancy rate of Saline sonosalpingogram.

\section{Methodology}

The study was conducted at an infertility clinic in private sector for 2 years from January 2015 to December 2016. It was a prospective randomized controlled trial. A total of 320 women attended infertility clinic during this period. Their age, parity, duration of infertility, previous history of menstrual cycle, abdominal and gynecological surgery, miscarriages and medical disorder were noted. Baseline investigation like blood group, hemoglobin percentage, hepatitis screening, hormone profile, ultrasonography, semen analysis of husband were planned to performed at first visit to infertility clinic. Inclusion criteria of the study were age up to 42 years with primary or secondary infertility of 2 years or more, regular menstrual cycle and all investigation within normal limit .Exclusion criteria were complete tubal blockage, male factor infertility, and active pelvic infection, major medical illness like uncontrolled diabetes, hypertension, hepatitis, renal or cardiac disease. Women who fulfilled the criteria were counseled about empirical nature of procedure and possible complication. 55 women were included in the study. After consent to participate in the study the participants were treated by ovulation induction by aromatase inhibitor $7.5 \mathrm{mg}$ once daily from $3^{\text {rd }}$ day to $7^{\text {th }}$ day of menstrual cycle. In this study group ovulation induction was followed by saline sonosalpingography done on day 9 or day 10 . The method consisted of passing Folly's catheter through the cervix and inflating balloon with $1.5 \mathrm{cc}$ distilled water. $60 \mathrm{cc}$ of normal saline was injected transcervically into the genital tract. Post procedure complication was reduced and patients were sent 
home on analgesic for 3 days. Ovulation was confirmed by follicular tracking on USG. Urine test for pregnancy was done if woman has missed period. Main outcome measure was number of conception.

\section{Results}

A total of 55 patients that had hydrotubation over a period of 2 years were analysed. Post saline sonosalpingography patency of the fallopian tubes confirmed with sonogram and $23(41.81 \%)$ patients were conceived. The mean age of the patients was the age range of 23 to 42 years.

Table 1: Distribution according to age group $(\mathbf{n}=55)$

\begin{tabular}{|l|c|c|}
\hline Age Group & Frequency & Percentage \\
\hline 23 to 27 Years & 26 & 47.27 \\
\hline $\mathbf{2 8}$ to 32 Years & 21 & 38.18 \\
\hline 33 to 37 Years & 7 & 12.7 \\
\hline 38 to 42 Years & 1 & 1.81 \\
\hline Total & $\mathbf{5 5}$ & $\mathbf{1 0 0 . 0}$ \\
\hline
\end{tabular}

Maximum patients were within the age of 23 to 27 years. $9(16.36 \%)$ patients have previous history of abortion and $2(3.64 \%)$ patients had history of ectopic pregnancy, 44(80\%) patients had no history of abortion. Primary infertility was the commonest type of infertility in 33(60\%) patients and 22(40\%) patients had been infertile for 2-15 years. Maximum patients were within the age range of 23-27 years (Table 1).

Table 2: Types of Infertility

\begin{tabular}{|l|c|c|}
\hline Type & Frequency & Percentage \\
\hline Primary & 33 & 60 \\
\hline Secondary & 22 & 40 \\
\hline Total & $\mathbf{5 5}$ & $\mathbf{1 0 0 . 0}$ \\
\hline
\end{tabular}

Patients with primary sub fertility were in $60 \%$ of total number of patients (Table 2).

Table 3: Duration of infertility

\begin{tabular}{|l|c|c|}
\hline $\begin{array}{l}\text { Duration of } \\
\text { Infertility }\end{array}$ & $\begin{array}{c}\text { Frequen } \\
\text { cy }\end{array}$ & Percentage \\
\hline 2 to 6 Years & 37 & 67.27 \\
\hline 7 to 11 Years & 15 & 27.27 \\
\hline $\begin{array}{l}\text { 12 to 15 } \\
\text { Years }\end{array}$ & 3 & 5.45 \\
\hline Total & $\mathbf{5 5}$ & $\mathbf{1 0 0 . 0}$ \\
\hline
\end{tabular}

Most of the patients are within 2 to 6 years of infertility. Out of 55 patients $23(41.81 \%)$ patients conceived after this procedure. Among them $17(30.9 \%)$ patients were suffering from primary infertility and 5(9.09\%) were suffering from secondary infertility (Table 3 ).

Total patency was confirmed in 55 patients by saline sonosalpingography with transvaginal sonography. All patients that had conceived in this study had evidence of tubal patency. There was no major complication recorded in this study that warrants hospitalization. Minor complication encountered were pelvic pain, slight vaginal bleeding. These patients were treated in outpatient basis or only by assurance.

The outcome of the 23 conceptions revealed that $12(52.17 \%)$ cases ended up in term pregnancy without any complication, 3(13.01\%) cases were twin pregnancy. Out of $3,1(4.3 \%)$ twin pregnancy completed by single fetus demise; $5(21.7 \%)$ cases were in missed abortion and $2(8.7 \%)$ cases in ectopic (Table 4).

Table 4: Outcome Success Rate $(n=55)$

\begin{tabular}{|l|c|c|}
\hline Success & Frequency & Percentage \\
\hline Patients conceived & 23 & 41.81 \\
\hline $\begin{array}{l}\text { Primary infertility } \\
\text { (patient } \\
\text { conceived) }\end{array}$ & 17 & 30.9 \\
\hline $\begin{array}{l}\text { Secondary } \\
\text { infertility (patient } \\
\text { conceived) }\end{array}$ & 5 & 9.09 \\
\hline
\end{tabular}

Out of 55 patients, 23(41.81\%) patients were conceived after this procedure, among them $30.9 \%$ were suffering from primary infertility and $9.09 \%$ were suffering from secondary infertility (Table 4).

Table 5: Outcome in pregnancy test positive cases $(\mathbf{n}=\mathbf{2 3})$

\begin{tabular}{|l|c|c|}
\hline $\begin{array}{l}\text { Outcome } \\
\text { Singleton } \\
\text { pregnancy } \\
\text { without any } \\
\text { complication }\end{array}$ & 12 & 52.17 \\
\hline Ectopic pregnancy & 2 & 8.7 \\
\hline $\begin{array}{l}\text { Twin pregnancy } \\
\text { with single fetus } \\
\text { demise }\end{array}$ & 1 & 4.3 \\
\hline Twin pregnancy & & \\
\hline Missed abortion & 5 & 13.01 \\
\hline
\end{tabular}




\section{Discussion}

The effect of saline sonosalpingography in infertility can be mechanical or immunological like Inhibit phagocytosis of spermatozoa or affecting level of peritoneal factors and cytokines. It is a non invasive cost effective first line therapy for selected infertile patients with cervical factor, unexplained infertility, and endometriosis. This randomized study aimed to investigate the therapeutic yields of saline infusion sonosalpingography performed 2 to 3 days before ovulation in stimulated cycles for couples with unexplained infertility.

The assessment of fallopian tubes patency is an integral and pertinent step in the evaluation of female infertility ${ }^{16}$, also the treatment of tubal factors on infertility management is most difficult and subject to debates ${ }^{15}$.

In this study sonosalpingography was used to assess the patency of fallopian tubes though not accurate as laparoscopy and dye test. Hydrotubation for therapeutic intervention was employed as a last resort of treatment for these patients because it is simple, cheap and minimally invasive procedure with low risk of complications. It was based on study by Johnson and Watson 6 that reported increased pregnancy with live birth rate.

Other study ${ }^{19}$ have reported fertility enhancing effect of tubal flushing especially with oil soluble medium, we used saline solution in our study due to side effect of oil media and because our intervention was principally for therapeutic reason. Oil media have been associated with allergy and anaphylaxis reaction from intravasation and formation of lipogranuloma on a long term. It is therefore not surprising that we only recorded minor complaints with the use of water medium in our study. The patients in our study series had pre partubation pelvic screening we were guided by the recommendation of Royal College of obstetricians and gynecologists ${ }^{20}$. And findings of clinical infection following hysterosulpingogram by Forsey et $\mathrm{al}^{20}$.

Post partubation sonogram was performed to assess patency of the fallopian tubes following the procedure. This was based on results of other studies that reported accuracy rate of diagnostic saline hysterosulpingogram ${ }^{18}$. On the whole $23(41.81 \%)$ conception rate recorded in patients with post partubation evidence of tubal patency by sonogram.
In this study overall conception rate of $41.81 \%$ recorded in 55 patients is similar in the study of A. G. Adesyn, that had therapeutic hydrotubation is encouraging. The hopeless natures of these cases are considered in this resource constrained setting. These procedures should be more effective in patients with perifimbrial adhesion followed by patients with unexplained infertility when combined with ovulation induction. The hypothesis is by Salak et $\mathrm{al}^{21}$ is same as this present study. Though use of oil soluble contrast is associated with increased in the odds of live births but not pregnancy rate when compare with water soluble media $^{21}$.

\section{Conclusion}

It has been found that therapeutic hydrotubation is beneficial in the management of female infertility, especially incomplete tubal occlusion and resource poor setting where modern technology and for management are mostly expensive and unavailable.

\section{References}

1. Mehmood G, Sadia S. Infertility Data of Maternal and Child Health Center, PIMS. J Surg Jun 2001;21-22:10-3

2. Edelstam G., Sjosten, A., BjurestenK,Ek L, Wanggren K. A new rapid and effective method for treatment of unexplained infertility. Hum Reprod. 2008;23:852-856

3. Wen $\mathrm{H}, \mathrm{Fu}$ J, Tang H, Ge M, Feng L. Hydrotubation combined with Chinese herbal medicine for salpingitic infecundity: a systematic review and meta-analysis. Cell Biochem Biophys 2015;71(2): 519-27

4. Yapca OE, Delibas IB, Karaca Time-limited I, Kum-tepe Y, Kadanali S. Time limited hydrotubation combi-ned with clomiphene citrate treatment for unexplained infertility. Clin Exp Obstet Gynecol 2015; 42 (3):311-4

5. Abbas A.M. Ovarian superstimulation and intra-uterine insemination for the treatment of unexplained infer-tility. Fertil Steril 1993; 60: 303-306

6. Zou S.E, Jin Y, Ko Y.L, Zhu J. A new classification system for pregnancy prognosis of tubal factor infer-tility. Int J Clin Exp Med 2014;7:1410-1416

7. Adesiyun A.G, Cole B, Ogwuche P. Hydrotubation in the management of female infertility: outcome in low resource settings. East Afr Med J 2009; 86: 31-36

8. Giuliano E, Cagnazzo E, Bazzan E, Patella A, Marci R. Hysterosalpingo - contrast sonography: Is it possible to quantify the therapeutic effect of a diagnostic test? Clin Exp Reprod Med. 2012;39(4): 161-165

9. Simsek E, Haydardedeoglu B, Hacivelioglu SO, Cok T, Parlakgumus A, Bagis T. Effect of cervical mucus aspiration before Intrauterine insemination. Int $\mathrm{J}$ Gynaecol Obstet 2008;103 (2):136-9

10. Walid A. Morad A, Ayman A. Abdelhamid. Prospec-tive randomized study for hydrotubation with or with-out lidocaine before intrauterine insemination in unex-plained infertility. Middle East Fertility Society Journal, 2012; 17: 250-255

11. Aboulghar M.A, Mourad L.M, Al-Inany H.G, Mansour R.T. Prospective randomized study for hydrotubation Versus no hydrotubation before intra-uterine insemi-nation 
in unexplained infertility. Reproductive Biomed 2010; 20 (4): 543-546

12. Schippert C, Soergel P, Staboulidou I, Rocha G. The risk of ectopic pregnancy following tubal reconstructive microsurgery and assisted reproductive technology procedures. Archives of Gynecology 2011;285(3):863-71

13. Duffy JM, Johnson N, Ahmad G, Watson A. Postoperative procedures for improving fertility following pelvic reproductive surgery. Cochrane Database Syst Rev 2009; (2): CD001897

14. Mohiyiddeen L, Hardiman A, Fitzgerald C, Hughes E, Mol BW, Johnson N, Watson A. Tubal flushing for subfertility. Cochrane Database Syst Rev 2015;(5):CD003718

15. EI-Mowfi DM, Ngoh NN. Management of tubal obstructions. Surg Technol Int 2005;14:199-212

16. Lupascu I, Veges S, Solomitchi V, et al. Sonohysterosalpingography in the assessment of tubal infertility. Rev Med Chir Soc Med Nat lasi 2003;107:841845
17. Vasiljevic, M., Ganovic, R., Jovanovic, R. and Markovic, A. Diagnostic value of hysterosalpingography and laparoscopy in infertile women. Srp Arh Celok Lek 1996; 124:135-38

18. Johnson NP, Watson A. Cochrane review: postoperative procedure for improving fertility following pelvic reproductive surgery. Hum Reprod Update 2000;6:259-67

19. Johnson NP, Farguhar CM, Hadden WE, et al. The flush trial flushing with lipiodal for unexplained and endometriosis related subfertility by hysteronsalpingography: a randomized trial. Hum Reprod 2004;19:2043-51

20. Forsey JP, Caul EO, Paul ID, Hull MGR. Chlamydia trachomatis, tubal disease and the incidence of symptomatic and asymptomatic infection following hysterosalpingography. Hum Reprod 1990;5:444-47

21. Sulak PJ, Letterie GS, Coddington CC, et al. Histology of proximal tubal occlusion. Fertil Steril 1987; 48: 437-40 